\title{
Utilização de ferramentas de idoneidade didática para análise do conceito de função em livros didáticos
}

\author{
Nádia Helena Braga \\ Vânia Maria Pereira dos Santos-Wagner
}

\begin{abstract}
Resumo: Este artigo é parte de uma pesquisa de doutorado em Educação Matemática. Apresenta uma análise do conceito intuitivo de função de um dos livros investigados e de uma atividade proposta aos alunos. $\mathrm{O}$ objetivo é trazer alguns aspectos de análise da abordagem do conceito de função em livros didáticos de Matemática da $1^{a}$ série do ensino médio adotados em escolas públicas brasileiras. Os componentes e indicadores da idoneidade epistêmica, cognitiva, instrucional e ecológica, que compõem as dimensões da idoneidade didática da Teoria do Enfoque Ontossemiótico do Conhecimento e Instrução Matemática (EOS) fundamentam esse estudo. Os achados podem auxiliar o professor a decidir como usar livros didáticos, superar algumas limitações de uso desses livros e enriquecer o planejamento de aulas ao introduzir outras tarefas que favoreçam a aprendizagem de estudantes.
\end{abstract}

Palavras-chave: Livro didático. Conceito de função. Educação matemática. Idoneidade didática. Enfoque ontossemiótico do conhecimento e instrução matemática.

Nádia Helena Braga Doutoranda em Educação pela Universidade Federal do Espírito Santo. Professor do Instituto Federal de Minas Gerais/campus Betim, Betim, Minas Gerais, Brasil.

http://orcid.org/0000-0002-8062-6905 $\triangle$ nadia.braga@ifmg.edu.br

Vânia Maria Pereira dos Santos-Wagner Doutora em Educação ( $\mathrm{PhD}$ in Mathematics Education) por Indiana University. Professora Colaboradora da Universidade Federal do Espírito Santo, Professora Aposentada da Universidade Federal do Rio de Janeiro, Brasil. D) http://orcid.org/0000-0001-9841-6191 $\triangle$ profvaniasantoswagner@gmail.com

Recebido em 30/06/2021 Aceito em 21/08/2021 Publicado em 06/09/2021

\section{Use of teaching tools for analysis of the function concept in textbooks}

Abstract: This article is part of a doctoral research in Mathematics Education. It presents an analysis of the intuitive concept of function of one of the investigated textbooks and of an activity proposed to the students. The objective is to bring some analysis' aspects of the approach to the concept of function in mathematics textbooks for the 1st grade of high school adopted in Brazilian public schools. The components and indicators of epistemic, cognitive, instructional and ecological suitability, which make up the dimensions of didactic suitability of the Theory of Ontosemiotic Approach to Mathematical Knowledge and Instruction (EOS) underlie this study. The findings can help the teacher to decide how to use textbooks, overcome some limitations in the use of these books, and enrich lesson planning by introducing other tasks that favor student learning.

Keywords: Textbook. Function concept. Mathematics education. Didactic suitability. Ontosemiotic approach to mathematical knowledge and instruction.

\section{Uso de herramientas didácticas para el análisis del concepto de función en los libros didácticos}

Resumen: Este artículo es parte de una investigación de doctorado en Educación Matemática. Presenta un análisis del concepto intuitivo de función de uno de los libros investigados y de una actividad propuesta a los estudiantes. Objetivo: traer algunos aspectos del análisis del abordaje del concepto de función en los libros de texto de Matemáticas para el 1er grado de secundaria adoptados en las escuelas públicas brasileñas. Los componentes e indicadores de idoneidad epistémica, cognitiva, instruccional y ecológica, que conforman las dimensiones de idoneidad didáctica de la Teoría del Enfoque Ontosemiótico del Conocimiento e Instrucción Matemática (EOS), sustentan este estudio. Los hachados pueden ayudar al maestro a decidir cómo usar los libros de texto, superar algunas limitaciones en el uso de estos libros y 
enriquecer la planificación de las lecciones al introducir otras tarefas que favorezcan el aprendizaje de los estudiantes.

Palabras clave: Libro de texto. Concepto de función. Educación matemática. Idoneidad didáctica. Enfoque ontosemiótico del conocimiento y la instrucción matemática.

\title{
1 Introdução
}

De acordo com Zuffi (1999), o conceito de função é um dos mais importantes conceitos da Matemática, devido ao seu papel central na matemática do ensino médio e em diversas disciplinas de formação básica nos cursos de graduação em Ciências Exatas, da Saúde e Sociais Aplicadas. Esse conceito está presente em todos os níveis de ensino, do fundamental ao superior, e é assunto frequente em livros didáticos, documentos oficiais e sistemas de avaliação nacionais e internacionais. Compreender como é feita a abordagem de funções nos livros pode trazer alguma luz sobre as dificuldades apresentadas pelos alunos na aprendizagem desse conceito. Neste texto1 apresentamos uma análise das características da lição² de um livro didático e uma atividade proposta pelo autor do livro, que aborda o estudo do conceito de função na $1^{\text {a }}$ série do ensino médio.

Este artigo traz um recorte de uma pesquisa de doutorado em andamento sobre a abordagem do conceito de função em livros didáticos de Matemática do ensino médio. Aqui é feita análise da idoneidade didática de uma lição sobre função trabalhada por Dante (2016) em um livro de matemática da primeira série do ensino médio. Buscamos em Breda, Font e Pino-Fan (2018), o significado de idoneidade didática.

\begin{abstract}
No EOS entende-se a idoneidade didática de um processo de ensino-aprendizagem como o grau em que este (ou uma parte dele) reúne certas características que permitem qualificá-lo como ótimo ou adequado para conseguir a adaptação entre os significados pessoais alcançados pelos estudantes (aprendizagem) e os significados institucionais pretendidos ou implementados (ensino), tendo em conta as circunstâncias e recursos disponiveis (entorno) (BREDA; FONT; PINO-FAN, 2018, p. 268 , tradução nossa) $)^{3}$.
\end{abstract}

Nesse sentido, pretendemos identificar em nossa análise o grau da idoneidade (adequação) didática da abordagem do conceito de função e da atividade proposta pelo autor do livro. Focalizamos em uma atividade proposta pelo autor para ser realizada pelos estudantes após

\footnotetext{
${ }^{1}$ Aqui amplia e aprofunda-se um trabalho apresentado no XI Seminário da Associação Nacional de Política e Administração da Educação (ANPAE), sob o título "Conceito de função em livros didáticos de Matemática" (2021).

2 Godino utiliza o termo "lição" para designar um tema matemático a ser estudado ou analisado.

3 Em el EOS se entiende la idoneidade didáctica de um processo de enseñanza-aprendizage como el grado em que éste (o una parte del mismo) reúne ciertas características que permitem calificarlo como óptimo o adecuado para conseguir la adaptación entre los significados institucionales pretendidos o implementados (enseñanza), teniendo em cuenta las circunstancias y recursos diponibles (entorno) (BREDA; FONT; PINO-FAN, 2018, p. 268).
} 
a apresentação intuitiva do conceito de função. Não se trata de abordar a análise global de um livro texto, desde uma perspectiva pedagógica, e sim de apresentar uma análise didática do desenvolvimento de um tema específico, neste caso o conceito de função. Esta análise orienta e identifica elementos que podem ser potencialmente conflitivos no processo instrucional que é proposto. A lição reflete o processo de instrução planejado pelo autor do livro como meio para professores alcançarem uma aprendizagem do conteúdo por parte dos estudantes. Dessa forma, surgiram os questionamentos: que tipo de situações são propostas pelo autor do livro didático para introduzir funções para os alunos da $1^{\text {a }}$ série do ensino médio? Qual é o grau de idoneidade (adequação) didática dessa abordagem segundo a teoria de EOS? Nesse artigo procuramos responder a essa segunda questão.

Concordamos com Broetto (2016), quando diz que o livro didático talvez seja o recurso mais utilizado pelos professores no ensino da educação básica. Algumas pesquisas relatam a respeito da utilização deste recurso pelos professores. Encontramos em Santos (2007), algumas evidências a esse respeito.

A metodologia que o professor utilizava na abordagem de alguns conteúdos refletia a mesma metodologia colocada pelo livro didático. [...] Os conteúdos desse livro estavam sistematicamente organizados e apresentados. [...] Além do uso dos LD alguns docentes utilizavam também a criatividade na elaboração de jogos e aulas no laboratório de matemática. [...] Seguia-se o mesmo método de resolução de sequências de exercícios e problemas similares aos propostos pelo livro (SANTOS, 2007, p. 14).

O professor encontra no livro a sequência do que deve ser ensinado, os exercícios para serem resolvidos, exemplos introdutórios, definições, explicações, justificativas; indica os que os alunos devem fazer; e, também, inclui elementos motivadores, entre outros. Santos (2007, p. 147) comenta que "o livro didático é um poderoso recurso utilizado pelos professores e alunos e colabora com a educação matemática no que ela tem a oferecer para a formação da cidadania".

Sabe-se que alguns professores utilizam os livros como recurso para planejarem suas aulas e/ou os utilizam direto como plano e roteiro de aulas. Parece que muitos professores acreditam que o conteúdo a ser ensinado, os exercícios e problemas a serem resolvidos já estão prontos e determinados no livro didático e que quase nada precisam acrescentar. Por um lado, isso parece facilitar o trabalho do professor, pois muitos creem que o livro traz tudo pronto, e que precisam apenas repassar os conceitos aos alunos. A nosso ver isso é um equívoco, pois assim estes professores nem estudam e analisam de forma crítica o livro adotado em suas escolas. Assim, nem refletem sobre os aspectos positivos e negativos do livro, nem planejam outras tarefas, e nem ampliam ideias do livro. Desta forma, com esta postura de uso do livro didático sem estudos 
e reflexão crítica, professores deixam de procurar outros livros e recursos que possam auxiliar os processos de ensino, aprendizagem e avaliação de matemática. Por sua vez, os estudantes utilizam o livro didático para estudar algum conteúdo, repetir exemplos e tarefas propostas, realizar pesquisas e fazer atividades.

Além de ser um recurso didático para o professor, os livros têm importância na transmissão do currículo prescrito em documentos oficiais. Pesquisas mostram que "Os livros didáticos são os principais transportadores do currículo e desempenham um papel dominante na educação atual em diferentes disciplinas escolares" (FAN; ZHU; MIAO, 2013, p. 635). Acreditamos que eles fazem uma transposição do currículo prescrito em documentos oficiais e apresentam aos professores uma tradução desse currículo a ser implementado em sala de aula. Concordamos com Santos (2007, p. 147) quando diz "É ele que muitas vezes estabelece o que ensinar". Entendemos que 0 livro didático carrega em si uma função mediadora, pois exerce ação entre o currículo prescrito e o currículo apresentado e implementado por professores em aulas.

Analisar livros didáticos é relevante para professores e pesquisadores, pois permite investigar currículos, práticas pedagógicas, concepções e possíveis usos do livro. Fan, Zhu e Miao (2013) alertam que muito pouco se pesquisou sobre os livros didáticos antes da década de 1980, e nas últimas três décadas a pesquisa sobre este recurso cresceu rapidamente. "Embora os livros didáticos fossem prevalentes nas salas de aulas, as investigações realizadas antes de 1980 eram inconclusivas, dispersas e muitas vezes trivial" (FAN; ZHU; MIAO, 2013, p. 633). A partir da década de 1980, as investigações versaram sobre vários temas, tais como: o papel dos livros didáticos; tipos de tarefas; diferenças entre abordagem de conteúdo; análise e comparação de livros didáticos; uso dos livros didáticos; e, ainda, sobre livros eletrônicos e a relação entre livros didáticos. Analisar a abordagem do conceito de função em livros didáticos pode contribuir para os conhecimentos curriculares e didático-matemáticos de professores e pesquisadores e nos oferecer condições de produzir significados para a matemática na sala de aula e fora dela.

Entre pesquisas internacionais encontram-se trabalhos que abordam análises de livros didáticos feitas por professores em formação (BLANCO; DOMÍNGUEZ, 2014; YILMAZ; GÜLBAGCI DEDE; AKKOÇ, 2020). Yang e Lin (2014) examinaram as diferenças de abordagem de funções entre livros de matemática finlandeses, de Singapura e taiwaneses do ensino médio. Özer e Sezer (2014) analisaram comparativamente perguntas em livros de matemática dos Estados Unidos, de Singapura e Turquia a partir de tópicos estudados no $8^{\circ}$ ano na Turquia. Burgos, Castillo, Pellicer, Giacomone e Godino (2020) utilizaram ferramentas teóricas do EOS para analisar o conteúdo de proporcionalidade em livros do sexto ano do curso de primária, com 
objetivo de ajudar os professores na tomada de decisões sobre as possibilidades e limitações dos livros didáticos. Fonseca (2013) avaliou a abordagem da função exponencial em manuais portugueses. Essa autora utilizou ideias teóricas de Godino e Batanero (1994) sobre EOS em suas análises. Urrea (2015) avaliou a representatividade dos significados pretendidos pelo currículo de matemática chileno sobre a noção de função em relação ao significado referencial holístico dessa noção. Armas (2016) utilizou as ferramentas do EOS e buscou avaliar a faceta epistêmica do conhecimento didático-matemático dos futuros professores de matemática. Malet, Giacomone e Repetto (2021) apresentam o estado da arte da utilização da Idoneidade Didática no período do 2005 a 2020. Os autores concluíram que a ferramenta foi mais utilizada para avaliação de processos de estudo e desenvolvimento da competência de reflexão didática na formação de professores. Godino, Bataneiro, Burgos e Gea (2021) fazem uma reflexão sobre o distanciamento existente entre a pesquisa e a prática docente. Eles indicam a Teoria da Idoneidade Didática (TID) como elo entre as pesquisas científico-tecnológica e a prática docente, no sentido de diminuir essa distância.

Pesquisas nacionais investigam possíveis relações entre documentos oficiais e os manuais didáticos (BARBOSA, 2017; MELO, 2018). Esses autores examinaram os documentos oficiais brasileiros e indicaram as aproximações entre esses documentos e o livro didático. Atayde (2010) analisou a abordagem da noção de função polinomial do $1^{\circ}$ grau em manuais escolares e se eles estavam propondo atividades que possibilitassem explorar as estratégias de resolução de problemas e investigação. Masetti (2016) abordou em seu estudo situações matemáticas, conceitos, proposições, procedimentos, linguagem, argumentação e tipos de tarefas que o livro texto apresenta a respeito da função exponencial. Lobo (2017) investigou os significados da variação, da taxa de variação e da derivada que podem ser construídos a partir da abordagem dos livros de matemática do ensino médio. Vieira (2016) pesquisou a coleção de livros de matemática usados em cursos técnicos integrados ao ensino médio. Ela investigou se a abordagem, contextualização e atividades propostas em cada série ajudariam na aprendizagem de disciplinas técnicas. Ninow (2019) desenvolveu e aplicou uma proposta de estudo com foco no ensino e aprendizagem de funções no ensino médio sob a perspectiva do EOS.

Para realizar análise sistemática da lição do livro didático aplicaremos as ferramentas de EOS propostas por pesquisadores espanhóis (CASTILLO; BURGOS; GODINO, 2021; GODINO; BATANERO, 1994; GODINO, BENCOMO, FONT, WILHELMI, 2006). 
central na linguagem, nos processos de comunicação e interpretação e na variedade de objetos que são colocados em jogo no ensino e aprendizagem da matemática (GODINO; CONTRERAS; FONT, 2006, p. 39, tradução nossa) ${ }^{4}$.

Diante dessas noções teóricas, nós elegemos como alicerce para este estudo a teoria de EOS e adaptamos as guias sugeridas por Castillo, Burgos e Godino (2021) para analisar livros didáticos. Castillo, Burgos e Godino (2021) esclarecem sobre a necessidade de se elaborar a guia:

[...] Não se trata de abordar a análise global de um livro didático, de uma perspectiva pedagógica, mas sim a análise didática do desenvolvimento de um tema específico. Para tanto, é necessário construir um guia que oriente a análise de uma forma geral, e posteriormente adaptá-lo a um tópico específico da matemática (CASTILLHO; BURGOS; GODINO, 2021, p. 6, tradução nossa) $)^{5}$.

A lição de um livro é um processo instrucional composto de uma sequência de atividades propostas pelo autor para o estudo do tema em questão, que aqui é o conceito de função. A sequência de atividades propostas no livro pode abordar ideias de origem histórica do conceito, formas intuitivas de explorá-lo e tarefas que provoquem a curiosidade dos alunos para examinarem conceitos matemáticos. Assim, vale a pena examinar como autores de livros didáticos fornecem exemplos introdutórios de conceitos ou procedimentos ou como são propostos problemas e exercícios a serem realizados pelos alunos. Portanto, os livros não só incluem o desenvolvimento do conteúdo matemático (faceta epistêmica, ou seja, conhecimentos institucionais planejados), mas também colocam em jogo os conhecimentos anteriores, ou conhecimentos prévios, que os estudantes devem ter para desenvolver e compreender um conceito novo introduzido na lição. Isso nos leva a crer que a análise de uma lição também deve ter em conta como estudantes usam e entendem alguns conhecimentos prévios, pois isso envolve investigar a faceta cognitiva (significados pessoais) de conceitos emergentes na mente de alunos.

Acreditamos que essas informações poderão ser úteis para professores e futuros professores que utilizem o livro como recurso didático, pois poderão identificar e conhecer conflitos epistemológicos e cognitivos quando usarem o livro em aulas. Além disso, poderão pensar, refletir, planejar e prever dificuldades de seus estudantes e uso de possíveis recursos didáticos para aulas.

\footnotetext{
${ }^{4}$ Godino y Batanero han desarrollado um conjunto de nociones teórica que configuram um enfoque ontológicosemiótico de la cognição matemática, em el que asignan um papel central al linguaje, a los processos de comunicación e interpretación y la variedade de objetos que se ponen em la enseñanza y el aprendizaje de las matemáticas (GODINO; CONTRERAS; FONT, 2006, p. 39).

${ }^{5}$ [...] no se trata de abordar el análisis global de un libro de texto, desde una perspectiva pedagógica, sino el análisis didáctico del desarrollo de una tema específico. Para conseguir dicho fin es necessário construir una guía que oriente el análisis de forma general, y posteriormente adaptar dicha guía a un tema de matemática en concreto (CASTILLHO; BURGOS; GODINO, 2021, p. 6).
} 
Supomos que professores e pesquisadores podem ampliar seus conhecimentos didáticomatemático referente ao conceito de função ao usarem as ideias de EOS.

Neste trabalho, além da introdução, o texto divide-se em cinco seções. Na segunda, descreve-se o objeto matemático funções. Na terceira, comenta-se a respeito de três conflitos epistêmicos associados ao conceito de função. Na quarta seção mostram-se quatro critérios de idoneidade didática e seus descritores usados nos procedimentos de análise. E na quinta seção apresenta-se uma análise do livro didático. Conclui-se esse texto na sexta seção, que mostra indícios de resultados de nossos questionamentos e do uso da guia de análise de EOS.

\section{0 objeto matemático funções}

Segundo as Orientações Curriculares para o Ensino Médio (OCEM) (BRASIL, 2006), o ensino de funções deve ser introduzido por meio da exploração qualitativa de relações entre duas grandezas em diferentes situações. Considera-se importante incentivar os estudantes para que apresentem outras relações, destacando o significado da representação de funções. Recomendase que a aprendizagem de um novo conceito matemático se inicie pela apresentação de uma situação-problema ao estudante, para provocá-lo a construir o conceito com significado ao relacioná-lo a seus conhecimentos prévios. Segundo a teoria de EOS, esses conceitos são epistêmicos porque se referem ao grau de representatividade dos significados institucionais (ou pretendidos) em relação aos significados de referência matemáticos que se espera que alunos compreendam, aprendam e saibam usar com entendimento relacional além de entendimento instrumental (SKEMP, 1976, 1993).

Em seguida, apresenta-se a ideia de modelagem matemática, que nesse documento OCEM (BRASIL, 2006, p. 85) é entendida como a "habilidade de transformar problemas da realidade em problemas matemáticos". Ressalta-se a importância da utilização da História da Matemática em sala de aula como um importante elemento no processo de atribuição de significados aos conceitos matemáticos e, ademais, que a tecnologia é um recurso importante que pode subsidiar o processo de aprendizagem da matemática. $O$ impacto da tecnologia no ensino é elucidado nas OCEMs.

Não se pode negar o impacto provocado pela tecnologia de informação e comunicação na configuração da sociedade atual. Por um lado, tem-se a inserção dessa tecnologia no dia a dia da sociedade, a exigir indivíduos com capacitação para bem usá-la; por outro lado, tem-se nessa mesma tecnologia um recurso que pode subsidiar o processo de aprendizagem da Matemática. É importante contemplar uma formação escolar nesses dois sentidos, ou seja, a Matemática como ferramenta para entender a 
tecnologia, e a tecnologia como ferramenta para entender a Matemática (BRASIL, 2006, p. 87).

Pondera-se nesse documento oficial como é importante olhar a história e, também, sobre a importância da utilização dos recursos tecnológicos para o ensino de funções, principalmente na construção e análise dos gráficos. Enfim, alguns softwares são dinâmicos e os alunos podem fazer mudanças nos parâmetros da função e visualizar as modificações que ocorrem no seu gráfico.

Os Parâmetros Curriculares Nacionais de Ensino Médio (PCNEM) (BRASIL, 2000) preconizam que o ensino do conceito de funções deve ser suficiente para que os estudantes possam tanto estabelecer as conexões com a própria matemática como adquirir certa flexibilidade para associá-lo às diversas situações em que possa estar presente. Deve-se incentivar 0 estudante a buscar soluções e ajustar seus conhecimentos sobre funções para, então, construir um modelo para interpretação e investigação em matemática. Zuffi (1999) argumenta que esse conceito de função tem aplicação nas mais diversas áreas do conhecimento e é o instrumento mais apropriado para o estudo das leis naturais. As OCEMs (BRASIL, 2006) propõem uma ação articulada dentro de cada área de conhecimento trabalhada no ensino médio e no conjunto das áreas, na qual os saberes se interligam e, eventualmente, ganham sentido.

O documento intitulado "As Orientações Educacionais Complementares aos Parâmetros Curriculares Nacionais, reformulação do ensino médio e áreas do conhecimento" [PCN+EM] (BRASIL, 2002) buscou atender à necessidade de atualização da educação brasileira, e exibiu neste documento um norte sobre o ensino de funções.

\footnotetext{
0 estudo das funções permite ao aluno adquirir a linguagem algébrica como a linguagem das ciências, necessária para expressar a relação entre grandezas e modelar situações-problema, construindo modelos descritivos de fenômenos e permitindo várias conexões dentro e fora da própria matemática. Assim, a ênfase do estudo das diferentes funções deve estar no conceito de função e em suas propriedades em relação às operações, na interpretação de seus gráficos e nas aplicações dessas funções (BRASIL, 2002, p. 121).
}

Concordamos com as premissas desse documento. Porém essas ações só podem acontecer se o professor tiver conhecimento da teoria de função, souber e quiser dialogar com seus alunos acerca delas e provocar diálogos entre alunos. Nesse caso essas ações podem ser exploradas pelo professor em aulas para auxiliar que seus estudantes tenham entendimento e integração do conceito de funções e suas diversas representações. Aprender matemática no ensino médio deve envolver entendimento relacional e ser mais do que memorizar resultados e ter apenas entendimento instrumental de uso de fórmulas e procedimentos (SKEMP, 1976; 1993). A aquisição e construção do conhecimento matemático na mente de cada estudante deve estar 
ligada ao domínio de um saber fazer e saber pensar e explicar matemática para si mesmo e outras pessoas.

Pensar no ensino de matemática no ensino médio, principalmente no que diz respeito ao conceito de funções, significa primeiramente rever e redimensionar o tema e rever a forma e metodologia de ensino. $\mathrm{O}$ documento PCEM traz esclarecimentos a respeito da metodologia de ensino.

De fato, não basta revermos a forma ou metodologia de ensino, se mantivermos 0 conhecimento matemático restrito à informação, com as definições e os exemplos, assim como a exercitação, ou seja, exercícios de aplicação ou fixação. Pois, conceitos que são apresentados de forma fragmentada, mesmo que de forma completa e aprofundada, nada garante que 0 aluno estabeleça alguma significação para as ideias isoladas e desconectadas umas das outras (BRASIL, 2000, p. 43).

Esse objeto de estudo torna-se mais compreensível quando se conhecem os vários caminhos percorridos ao longo do tempo na sua construção. Sabemos que os alunos têm dificuldades na aprendizagem do conceito de função. Em vista destas dificuldades, vários estudos relacionados ao ensino e aprendizagem apontaram os conflitos epistêmicos associados ao conceito de função que exibiremos na seção seguinte.

\section{Conflitos epistêmicos associados ao conceito de função}

No processo de ensino das funções, a diferença de significado entre uma representação e outra gera conflitos, que ocasionam obstáculos de compreensão do conceito (ARMAS, 2020; NINOW, 2019; SIERPINSKA, 1992; ZUFFI, 1999). "Os obstáculos de origem epistemológica são aqueles que se observam no desenvolvimento histórico dos conhecimentos e cuja rejeição precisou ser integrada explicitamente no saber transmitido" (ZUFFI, 1999, p. 16). O estudo de situações-problema, que envolvem relações funcionais em diferentes períodos históricos, tem permitido distinguir diferentes conflitos epistêmicos associados à noção de função. Considera-se como obstáculos epistêmicos os desajustes entre 0 pretendido institucionalmente e 0 implementado pelo docente em sua classe e o que é realmente aprendido pelo aluno (GODINO, et al. 2006). Por esse motivo, é necessário analisar esses obstáculos epistêmicos por quem orienta o processo de ensino, que é o professor ou a professora regente de sala e/ou formadores de professores e pesquisadores.

Essas análises ajudam a identificar desequilíbrios cognitivos que possam ocorrer no processo de aprendizagem dos estudantes. Esses desequilíbrios ou conflitos cognitivos podem 
ser minimizados em aulas se professores aproveitarem essas análises para organizar e orientar processos de ensino e de aprendizagem. Para que os conflitos epistêmicos sejam úteis no processo de aprendizagem, é necessário que o docente possa produzir e analisar os elementos matemáticos primários do objeto matemático que estuda. Alguns pesquisadores, tais como Sierpinska (1992), Zuffi (1999), Barreto (2009), Font (2011), Ninow (2019) e Armas (2020) salientam os principais conflitos epistêmicos que identificamos no estudo de funções:

Não reconhecer a letra como variável - esse é um conflito muito comum, que consiste na não aceitação da letra como uma quantidade suscetível de trocas e, portanto, não reflete na quantificação das referidas alterações. 0 aluno percebe a variável na função como se fosse a incógnita de uma equação e tenta encontrar um valor para essa incógnita. Esse conflito foi relatado por Sierpinska (1992), Zuffi (1999) e Armas (2020), entre outros. Sierpinska (1992) preleciona que, antes de aprender funções, a experiência que os alunos têm com variáveis é aquela em que a distinção fundamental é feita entre quantidades dadas e as desconhecidas, o que os leva a pensar em termos de equações e desconhecidos a serem extraídos delas.

Não aceitação de representações diferentes da analítica como representação de uma função - é um conflito observado em quase todos os níveis acadêmicos. Consiste em que a única representação reconhecida para uma função é a aritmética numérica ou a aritmética algébrica, apresentada em uma fórmula ou um polinômio aritmético. Uma tabela, um gráfico, um diagrama, uma sequência numérica e pares ordenados não são considerados como representação de função. Esse conflito gera dificuldade na integração entre os distintos registros e representações (ARMAS, 2020) e não concebem uma relação funcional como função.

Confundir a letra como grandeza com a letra como variável generalizada - esse conflito com características do descrito anteriormente também apresenta-se praticamente em todos os níveis acadêmicos. Esses conflitos são transmitidos de geração em geração, dessa forma, sua origem parece ser epistemológico-didática. Ao se modelar relações funcionais com expressões algébricas do tipo $e=v t-g t^{2} / 2$ (em que e representa o espaço percorrido por um móvel lançado no espaço, $v$ a velocidade, $g$ a gravidade nesse lugar e t o tempo gasto no percurso) $\mathrm{e}$ considerá-la equivalente à fórmula matemática $y=a x-b x^{2} / 2$, a passagem está sendo feita das grandezas concretas - de espaço e tempo - para as variáveis gerais ( $x$ e y) (FONT, 2011). Sierpinska (1992) mostra que ao trabalhar com o sistema de eixos cartesianos, chama-se o eixo horizontal de $x$ - 0 eixo das abscissas - e o eixo vertical de y - eixo das ordenadas. Mas essas denominações são arbitrárias, convencionais. Assim, o conjunto $\{(x, y): y=x 2\}$ tem o mesmo significado de tratar com o conjunto $\{(y, x): x=y 2\}$, todavia, esse processo de analogia não pode 
ser aplicado em contextos da Física, uma vez que na lei de Galileu, $s=\frac{1}{2} g t^{2}$, a variável "s" não deve ser mudada para a variável "t". A teoria de EOS permite esclarecer e conhecer melhor a respeito dos conflitos cognitivos e epistêmicos no ensino. Na seção seguinte mostram-se os critérios de idoneidade propostos por Godino et al. (2006).

\section{Critérios de idoneidade didática e seus descritores}

A lição em um livro didático é considerada como um processo instrucional (previsto ou planejado), e as ferramentas elaboradas pela teoria de EOS podem ser aplicadas para análise sistemática de lições dos livros didáticos (CASTILLO; BURGOS; GODINO, 2021; GODINO, 2002; GODINO; BATANERO, 1994; GODINO; BATANERO; FONT, 2007; GODINO; BATANERO; FONT, 2008; GODINO et al., 2006). Godino e colaboradores elaboraram um sistema de noções teóricas sobre a natureza, origem e significado dos objetos matemáticos desde uma perspectiva educativa, quando trataram de articular de modo coerente as dimensões epistêmicas (significados institucionais ou socioculturais) e cognitiva (significados pessoais, psicológicos ou individuais) (GODINO, 2002; GODINO; BATANERO, 1994; GODINO; CONTRERAS; FONT, 2006; GODINO et al., 2006). Aspirar à melhora do funcionamento dos processos de ensino e aprendizagem da matemática implica a necessidade de obter critérios de idoneidade ou adequação didática que permitam avaliar os processos de instrução efetivamente realizados e orientar uma possível melhora.

Entende-se "critério de idoneidade como uma norma de correção, que estabelece como deveria ser realizado um processo de ensino e aprendizagem" (BREDA, FONT, PINO-FAN, 2018, p. 264- Tradução nossa)6. Godino, Contreras e Font (2006) introduziram a noção de idoneidade ou adequação de um processo de ensino matemático como uma ferramenta para estabelecer uma ponte entre a didática descritiva e a didática normativa ou técnica. Essas idoneidades têm como objetivo avaliar as diferentes trajetórias nos processos de ensino efetivos em contraste aos processos de estudos potenciais. Pode-se dizer que a idoneidade didática é um critério de adequação ao projeto de ensino, que tem como indicador a adaptação entre os significados pessoais alcançados pelos estudantes e os significados institucionais pretendidos/implementados pelos professores.

\footnotetext{
6 Critério de idoneidade se debe entender una norma de correción que estabelece como debería realizar-se um processo de enseñanza y aprendizaje (BREDA, FONT, PINO-FAN, 2018, p. 264).
} 
Como já mencionado, este trabalho pretende analisar a apresentação do conceito de função em um livro didático e uma atividade sobre o tema proposta pelo autor do livro didático. Adotou-se a guia proposta por Castillo, Burgos e Godino (2021), adaptando os indicadores de idoneidade epistêmica, idoneidade cognitiva, idoneidade instrucional e idoneidade ecológica aos conhecimentos didático-matemáticos de professores sobre o conceito de função. A guia de análise proposta na teoria de EOS nos oferece as ferramentas necessárias para analisar detalhadamente as situações-problema, as representações, os conceitos, os procedimentos, as proposições e argumentos envolvidos. Ademais, pretenderam-se identificar os conhecimentos prévios, que são requeridos ao longo do processo de ensino-aprendizagem, os recursos didáticos propostos e os modos de interação propostos entre professor e estudantes e entre estudantes. Objetivou-se identificar os conflitos epistêmicos e cognitivos instrucionais.

A seguir, exibem-se, de maneira detalhada, os critérios de idoneidade e os descritores de cada um deles, além de explicitar como eles se fazem operativos para avaliar os processos de instrução matemática e justificar os aspectos a serem melhorados. Godino, Batanero e Font (2008) definem a idoneidade didática de um processo de instrução como a articulação coerente e sistêmica de seis dimensões/níveis relacionadas entre si, as quais são apresentadas na Tabela 1. Essas dimensões ou níveis de análise são avaliados conforme o grau de representatividade (alto, médio ou baixo) em um processo de estudo pretendido ou implementado.

Tabela 1 - Componentes e características da idoneidade didática

\begin{tabular}{l|l}
\hline \hline \multicolumn{1}{c}{ Componente } & \multicolumn{1}{c}{ Característica } \\
\hline Idoneidade epistêmica & $\begin{array}{l}\text { Refere-se ao grau de representatividade dos significados institucionais implementados } \\
\text { ou pretendidos, em relação a um significado de referência. }\end{array}$ \\
\hline Idoneidade cognitiva & $\begin{array}{l}\text { Expressa o grau em que os significados pretendidos/implementados estão na área de } \\
\text { desenvolvimento potencial dos estudantes, bem como o grau de proximidade entre os } \\
\text { significados pessoais atingidos e os significados pretendidos/implementados. }\end{array}$ \\
\hline Idoneidade ecológica & $\begin{array}{l}\text { Grau em que o processo de estudo se ajusta ao projeto educacional, a escola, a } \\
\text { sociedade e ao ambiente em que se desenvolve. }\end{array}$ \\
\hline Idoneidade afetiva & $\begin{array}{l}\text { Grau de envolvimento dos alunos no processo de ensino. Está relacionada a fatores } \\
\text { que dependem da instituição, do aluno e da sua história escolar prévia. }\end{array}$ \\
\hline $\begin{array}{l}\text { Idoneidade } \\
\text { interacional }\end{array}$ & $\begin{array}{l}\text { Está relacionada ao processo de ensino e aprendizagem. Volta-se para a identificação } \\
\text { e resolução dos conflitos semióticos produzidos durante o processo de ensino. }\end{array}$ \\
\hline Idoneidade mediacional & $\begin{array}{l}\text { Grau de disponibilidade e adequação dos recursos necessários para o desenvolvimento } \\
\text { do processo de ensino e aprendizagem. }\end{array}$ \\
\hline Fonte:Adaptado de Godino
\end{tabular}

Fonte: Adaptado de Godino, Batanero e Font (2008).

Nesse sentido, ao aplicar as ferramentas de análise didática da teoria de EOS para avaliar o processo de ensino desse tema pode-se identificar possíveis conflitos de sentido, e assim poderá haver melhorias do processo educativo. De acordo com o marco teórico do EOS, a reconstrução dos significados da função é um primeiro passo necessário para poder compreender os processos 
de ensino efetivamente implementados e elaborar critérios para sua melhoria. 0 conceito de função é um bom exemplo para mostrar a diversidade de sistemas de práticas e contextos de uso mais amplos, entendidos no EOS como subsistema de práticas.

Procuramos investigar no livro didático a idoneidade didática de um processo de estudo matemático, tendo em conta as distintas dimensões implicadas, assim como o modelo epistemológico, cognitivo, instrucional e ecológico proposto pelo EOS. Em seguida, apresentamse as guias para a análise das idoneidades epistêmica, cognitiva, interacional e ecológica, que foram adaptadas de Castillo, Burgos e Godino (2021) para produzir uma análise inicial da abordagem do conceito de função em alguns livros didáticos de matemática da $1^{\mathrm{a}}$ série do ensino médio.

\subsection{Idoneidade epistêmica}

Tabela 2: Componentes e indicadores de idoneidade (adequação) epistêmica

\begin{tabular}{|c|c|}
\hline Componentes & Indicadores \\
\hline Situações-problema & $\begin{array}{l}\text { Se, nos livros didáticos, existe uma mostra representativa e articulada de situações } \\
\text { (elementos introdutórios, exemplos, exercícios para fixação de aprendizagens) que } \\
\text { provoquem curiosidade e desejo de aprender e entender conceitos. } \\
\text { Propõem situações de generalização de problemas (problematização). }\end{array}$ \\
\hline Linguagens & $\begin{array}{l}\text { Se usam diferentes tipos de linguagem (verbal, gráfica, simbólica). Se o nível de } \\
\text { linguagem é adequado aos alunos (faixa etária, experiências escolares e extraescolares, } \\
\text { interesses) aos quais se dirige. }\end{array}$ \\
\hline $\begin{array}{l}\text { Conceitos, Proposições, } \\
\text { Procedimentos }\end{array}$ & $\begin{array}{l}\text { Se apresentam com clareza os conceitos fundamentais, proposições e procedimentos de } \\
\text { forma correta e adaptados ao nível educacional ao qual se dirigem. } \\
\text { Se propõem situações nas quais os alunos precisam negociar definições, proposições e } \\
\text { procedimentos. }\end{array}$ \\
\hline Argumentos & $\begin{array}{l}\text { Se as proposições e procedimentos são explicados e argumentados (justificados e } \\
\text { demonstrados) de forma adequada de acordo com o nível educacional ao qual se dirigem. } \\
\text { Se a justificação de afirmações e proposições matemáticas é favorecida por vários tipos } \\
\text { de raciocínio e métodos de teste. }\end{array}$ \\
\hline Relações & $\begin{array}{l}\text { Se os objetos matemáticos (problemas, definições, proposições, etc.) se relacionam e } \\
\text { conectam entre si. } \\
\text { Se os vários significados dos objetos que intervêm nas práticas matemáticas são } \\
\text { identificados e articulados. }\end{array}$ \\
\hline $\begin{array}{l}\text { Comunicação e } \\
\text { argumentação }\end{array}$ & $\begin{array}{l}\text { Se são promovidas situações em que o aluno deve argumentar (descrever, explicar, } \\
\text { verificar) e formular conjecturas sobre relações matemáticas, investigá-las e justificá-las. } \\
\text { Se são propostas situações que permitem ao aluno comunicar-se usando linguagem } \\
\text { matemática para expressar suas ideias com precisão. } \\
\text { Se são propostas situações em que o aluno pode analisar e avaliar o pensamento } \\
\text { matemático e as estratégias dos outros. }\end{array}$ \\
\hline Modelização & $\begin{array}{l}\text { Se são propostas situações que permitem ao aluno utilizar modelos matemáticos para } \\
\text { representar e compreender relações quantitativas (identificar, selecionar características } \\
\text { de uma situação, representá-las simbolicamente, analisar e raciocinar o modelo, } \\
\text { reconhecer as características da situação, a precisão e as limitações do modelo). } \\
\text { Se o uso de tecnologia e o uso de funções para modelar padrões de mudança quantitativa } \\
\text { são promovidos. }\end{array}$ \\
\hline Generalização & $\begin{array}{l}\text { Se são incentivadas situações em que os alunos têm a oportunidade de descrever, } \\
\text { explicar e fazer generalizações e conjecturas de padrões geométricos e numéricos. }\end{array}$ \\
\hline Conflitos epistêmicos & $\begin{array}{l}\text { Se os conteúdos, situações-problema e suas soluções, conceitos, proposições, linguagem } \\
\text { etc. são apresentados corretamente sem erros, contradições, ambiguidades. }\end{array}$ \\
\hline
\end{tabular}


Fonte: Adaptada de Castillo, Burgos e Godino (2021).

\subsection{Idoneidade cognitiva}

Tabela 3: Componentes e indicadores da idoneidade (adequação) cognitiva

\begin{tabular}{l|l}
\hline \multicolumn{1}{c|}{ Componentes } & \multicolumn{1}{c}{ Indicadores } \\
\hline Relações & $\begin{array}{l}\text { Se as experiências (situações, exemplos, explicações) propostas permitem avaliar se o } \\
\text { aluno estabelece relações ou conexões entre os objetos matemáticos e seus significados } \\
\text { correspondentes. }\end{array}$ \\
\hline Conhecimentos prévios & Se o texto contempla os conhecimentos prévios necessários para o estudo do tema. \\
\hline Conflitos cognitivos & $\begin{array}{l}\text { Se prevê possíveis conflitos cognitivos dos alunos. Se o erro é valorizado como fonte de } \\
\text { aprendizagem. } \\
\text { Se inclui propostas de atividades para detectar ideias, erros ou dificuldades anteriores dos } \\
\text { estudantes em relação a esse conteúdo. }\end{array}$ \\
\hline
\end{tabular}

Fonte: Adaptada de Castillo, Burgos e Godino (2021)

\subsection{Idoneidade instrucional}

Tabela 4: Componentes e indicadores de idoneidade (adequação) interacional

\begin{tabular}{|c|c|}
\hline Componentes & Indicadores \\
\hline Interação autor-aluno & $\begin{array}{l}\text { Se o autor faz uma apresentação adequada do tema (apresentação clara e bem- } \\
\text { organizada, enfatiza os conceitos chaves do tema, etc.) } \\
\text { Se a inclusão dos alunos na dinâmica da exposição é promovida ou facilitada. }\end{array}$ \\
\hline Interações discentes & $\begin{array}{l}\text { Se propõem tarefas que favorecem o diálogo, comunicação e debate entre os estudantes, } \\
\text { nas quais diferentes pontos de vista são explicados, justificados e questionados com base } \\
\text { em argumentos matemáticos. } \\
\text { Se são apresentadas situações em que os alunos devem convencer a si próprios e aos } \\
\text { outros da validade das suas afirmações, conjecturas e respostas, baseando-se em } \\
\text { argumentos matemáticos. }\end{array}$ \\
\hline Autonomia & $\begin{array}{l}\text { Se há momentos em que os alunos assumem a responsabilidade pelo estudo (fazer } \\
\text { perguntas e apresentar soluções; explorar exemplos e contraexemplos para investigar e } \\
\text { conjecturar; usar uma variedade de ferramentas para raciocinar, fazer conexões, resolver } \\
\text { problemas e se comunicar). }\end{array}$ \\
\hline
\end{tabular}

Fonte: Adaptada de Castillo, Burgos e Godino (2021).

\subsection{Idoneidade ecológica}

Tabela 5: Componentes e indicadores de idoneidade (adequação) ecológica

\begin{tabular}{l|l}
\hline \multicolumn{1}{c|}{ Componentes } & \multicolumn{1}{c}{ Indicadores } \\
\hline Abertura à inovação & Se tem inovação baseada na pesquisa e prática reflexiva. \\
\hline Adaptação socioprofissional & Se os conteúdos contribuem para a formação socioprofissional dos alunos. \\
\hline Educação em valores & $\begin{array}{l}\text { Se é contemplada a formação em valores democráticos (respeito à diversidade, } \\
\text { tolerância, integração, cooperação, consciência ambiental e pacifismo). } \\
\text { Se oportuniza para que os alunos questionem, critiquem e reflitam (pensamento crítico). }\end{array}$ \\
\hline $\begin{array}{l}\text { Conexões intra e } \\
\text { interdisciplinares }\end{array}$ & $\begin{array}{l}\text { Se os conteúdos oferecidos estão relacionados a outros conteúdos intra e } \\
\text { interdisciplinares (temas transversais, história da matemática, entre outros). }\end{array}$ \\
Fonte: Adaptada de Castillo, Burgos e Godino (2021).
\end{tabular}


Essas ferramentas podem ser aplicadas à análise de um processo pontual de estudo implementado numa sala de aulas, ao planejamento ou ao desenvolvimento de uma unidade didática ou a um nível mais global, por exemplo, o desenvolvimento de um curso ou de uma proposta curricular. Elas também podem ser úteis para analisar aspectos parciais de um processo de estudo, material didático, um livro didático e respostas dos estudantes a tarefas específicas. Aqui, como já informado, serão usadas para analisar e investigar a abordagem de função em um livro didático e em uma lição.

\section{Análise do livro didático}

Realizamos neste estudo vários procedimentos metodológicos. Iniciamos fazendo um percurso pelo livro, observando a estrutura, as figuras, o número de páginas e as subdivisões dos capítulos. Em outro percurso, fizemos a leitura da apresentação da obra feita pelo autor do livro. Voltamos a folhear o livro para identificar as orientações dadas no início e no manual do professor. Navegamos por cada capítulo, observando as situações-problema, os exemplos, tipos e quantidades de exercícios propostos. Realizamos, posteriormente, esses procedimentos diversas vezes ao ler, reler e registrar detalhes identificados no capítulo que introduz o conceito de função. Assim, buscamos evidenciar as idoneidades epistêmica, cognitiva, instrucional e ecológica do conceito de função e da atividade proposta aos alunos pelo autor do livro, segundo a Tabela 1.

Aqui se descreve a respeito do livro didático ${ }^{7}$ e faz-se uma análise da abordagem do conceito de função. A lição ora analisada é o capítulo 2 da unidade 1 do livro Matemática: Contexto \& Aplicações, de Luiz Roberto Dante (2016). Esse é o volume 1, destinado aos alunos da $1^{\text {a }}$ série do ensino médio. Os alunos brasileiros de escolas públicas recebem o livro gratuitamente do Governo Federal por meio do Programa Nacional do Livro Didático (PNLD). A escolha por essa obra deu-se por ser a coleção de maior distribuição no território nacional.

Dante (2016) informa que o livro tem o intuito, numa perspectiva metodológica, de desenvolver competências e habilidades em matemática de tal forma que o jovem possa enfrentar situações que poderão surgir ao longo da vida. Explorou os conceitos básicos de maneira intuitiva e compreensível. Evitou trazer receitas prontas e formalismo excessivo, mas manteve o rigor coerente com o nível de ensino. No capítulo 2, ele traz um pouco da história das funções, explora intuitivamente a noção de função e, em seguida, a noção de função por meio de conjuntos, com sua definição e notação. Apresenta o domínio, contradomínio e imagem. Faz um estudo do

\footnotetext{
7 Uma das autoras já trabalhou em sala de aula de ensino médio com a obra que está sendo analisada.
} 
domínio das funções reais, coordenadas cartesianas, representação gráfica, crescimento e decrescimento de funções, análise de gráficos, função injetiva, sobrejetiva e bijetiva e finaliza apresentando a relação entre função e sequências, sendo estas aritméticas e geométricas. Ele organiza o livro em conformidade com algumas pesquisas realizadas sobre 0 ensino e aprendizagem do conceito de função (NINOW, 2019; SIERPINSKA, 1992; ZUFFI, 1999)

A obra traz para os estudantes exercícios de vestibulares de Norte a Sul do Brasil e questões do Exame Nacional do Ensino Médio (ENEM) dentro da temática estudada. Nas orientações aos professores são sugeridas atividades em grupos ou em duplas, para provocar a interação entre os alunos. Consideramos que o autor ao oferecer aos estudantes uma diversidade de atividades aumenta as idoneidades epistêmicas, cognitiva e interacional. A análise deste artigo focalizou-se na noção intuitiva de função apresentada pelo autor e exemplos propostos aos alunos. Logo após a noção intuitiva, destaca-se uma atividade para relatar a análise de sua idoneidade (adequação) didática. Na seção 2 do livro inicia-se o tema: explorando intuitivamente a noção de função por meio de quatro exemplos, sendo dois exemplos contextualizados dentro da própria matemática e, os outros dois contextualizados no meio sociocultural. Verificamos que a obra segue um padrão: as noções matemáticas a serem trabalhadas são propostas com exemplos ou atividades resolvidas, e depois disso o autor oferece uma série de exercícios para serem resolvidos. Escolhemos o primeiro exemplo porque ele exibe uma situação do meio sociocultural, explora os modos diferentes para se representar a função. Esse conceito de função é apresentado de forma intuitiva, por meio desse exemplo inicial de acordo com a Figura 1.

Figura 1: Exemplo de noção intuitiva de função

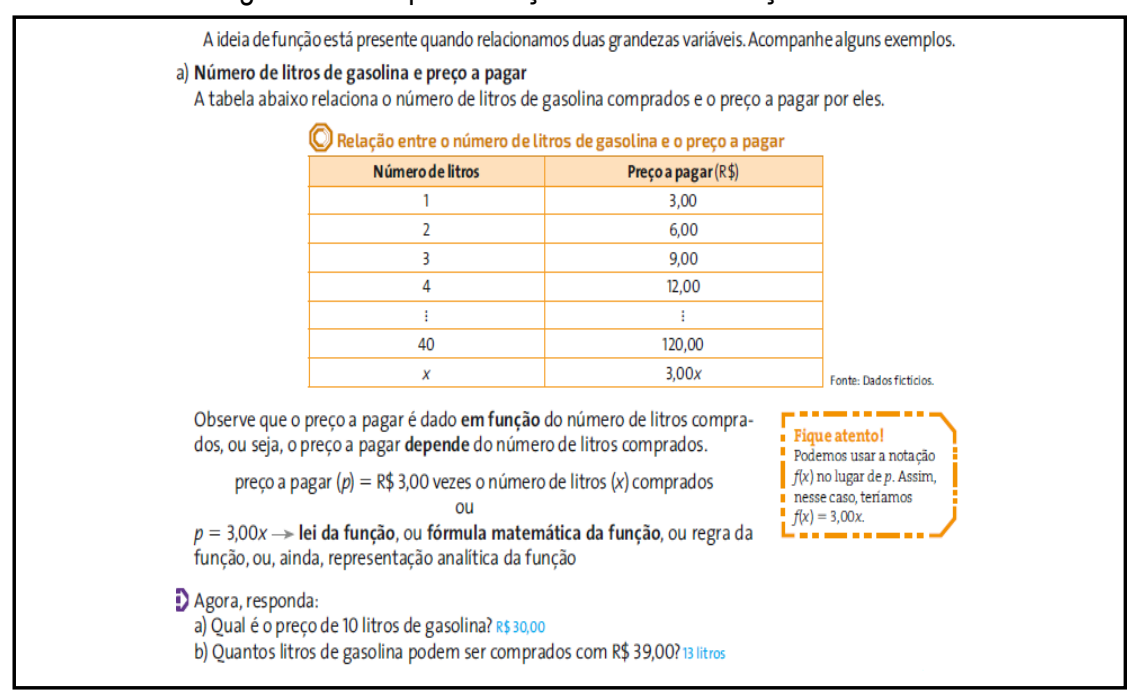

Fonte: Dante (2016, p. 45). 
Dante (2016) inicia a exposição da noção intuitiva de função apresentando um exemplo por meio de uma tabela com grandezas variáveis. Neste caso, as grandezas estão relacionadas ao volume (litros de gasolina) e o valor a ser pago por litro. 0 problema traz uma amostra representativa e articulada de uma situação-problema, contextualizada do meio sociocultural dos alunos e busca ampliar o conhecimento matemático que assinalamos como indicador da idoneidade epistêmica. Ao propor situações do cotidiano, o autor atende às Orientações Curriculares que trazem as condições que favorecem a aprendizagem. "A riqueza de situações envolvendo funções permite que o ensino se estruture permeado de exemplos do cotidiano, das formas gráficas que a mídia e outras áreas do conhecimento utilizam para descrever fenômenos de dependência entre grandezas" (BRASIL, 2006, p.121). Utiliza-se a linguagem verbal adequada ao nível de ensino e esclarece o que são variáveis dependentes e independentes. Conduz 0 aluno a adquirir a linguagem algébrica, modelar a situação-problema e construir conexões dentro e fora da própria matemática. Observamos que as idoneidades epistêmica, cognitiva, interacional e ecológica estão presentes na forma como o autor expõe a noção intuitiva de função.

O exemplo proposto faz conexão entre a representação tabelar e a representação analítica de uma função e provoca no aluno questionamentos e argumentações quanto à funcionalidade das variáveis. Neste caso a função é linear do tipo $y=k x$, onde $\mathrm{k}$ é uma constante. $\mathrm{A}$ idoneidade cognitiva e interacional é identificada quando o autor propõe perguntas para 0 aluno responder relativas ao valor a pagar e quanto de combustível pode-se calcular de acordo com determinado valor. Esses jovens, mobilizarão conhecimentos prévios de multiplicação e divisão de números naturais. Assegura-se desta forma, que eles apresentem os conhecimentos prévios necessários para o estudo do tema e que o conteúdo que se pretende ensinar seja alcançado. Acreditamos que ao fazer emergir os conhecimentos prévios dos estudantes, o autor aumenta a idoneidade cognitiva. No balão ao lado da Figura observa-se que o autor interage com o professor e os alunos quando sugere mudança da letra $p$ (preço a pagar) pela notação $f(x)$ e apresenta-se a função $f(x)=3,00 x$, que é definida como a lei de formação geral da função. 0 autor apresenta a notação analítica de função, que de acordo com os pesquisadores é de difícil entendimentos para os alunos (NINOW, 2019; SIERPINSKA, 1992; ZUFFI, 1999).

O quarto exemplo ilustrado na Figura 2, é uma adaptação artificial da realidade e está relacionado a outra Ciência. Ele envolve conhecimentos de velocidade média da Física. A nossa opção por esta situação-problema está na importância da aplicação dos conhecimentos matemáticos permitindo várias conexões dentro e fora da própria matemática. Esse procedimento nós identificamos com as conexões intra e interdisciplinar da idoneidade ecológica. Por meio de 
uma linguagem expositiva, apresenta-se ao aluno, em uma tabela, a relação entre tempo e distância percorrida, levando-o a perceber a relação funcional entre as grandezas e ao mesmo tempo a fazer conexões entre a representação tabelar e analítica. Representa a distância percorrida com a letra d e o tempo com a letra t e modeliza-se a distância em função do tempo, $d=90 t$. Ao estabelecer as letras d para distância e t para o tempo, evita-se um obstáculo cognitivo de confundir a letra como grandeza com a letra como variável generalizada (SIERPINSKA, 1992; ZUFFI, 199; NINOW, 2019; ARMAS, 2020). Os indicadores da idoneidade epistêmica e Idoneidade cognitiva são identificados quando se mobiliza os conhecimentos prévios de razão e proporção, ao perguntar se a distância percorrida é diretamente proporcional ao intervalo de tempo. E ainda, os estudantes deverão perceber que a velocidade é uma razão constante. Segundo Dante (2016, p. 121) "Tradicionalmente o ensino de funções estabelece como pré-requisito o estudo dos números reais e de conjuntos e suas operações, para depois definir relações e a partir daí identificar as funções como particulares relações". O autor introduz os novos conhecimentos suportados pelos conhecimentos anteriores.

Figura 2: Exemplo de noção intuitiva de função com aplicação em outra Ciência

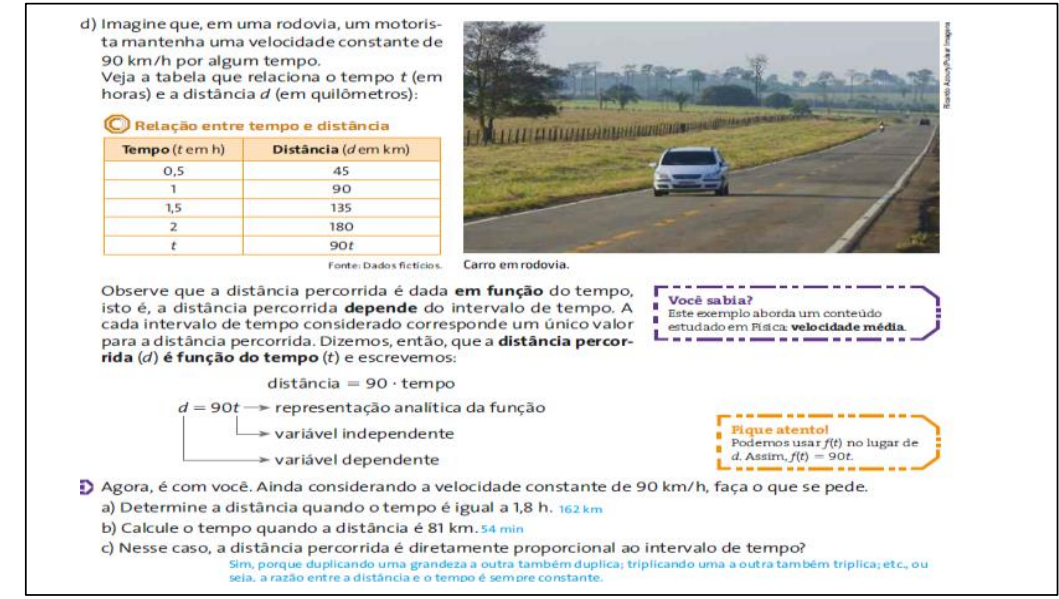

Fonte: Dante (2016, p. 46).

Observamos que os exemplos trazem uma linguagem clara, adequada ao nível de ensino, transita entre diversas formas de representar a situação-problema, traz interação entre autor, professor e alunos quando faz sugestões nos balões que acompanham os exemplos e, também quando propõe questionamentos para os estudantes responderem. Conduz com clareza as etapas de apresentação e resolução, atende as Orientações Curriculares e aos indicadores da idoneidade epistêmica, cognitiva, interacional e ecológica, propostos pelos pesquisadores espanhóis.

Ao finalizar a introdução intuitiva do conceito de função, a obra oferece aos alunos 10 exercícios, que exigem conhecimentos prévios de Geometria (área do quadrado e diagonal), custo de produção e custo de venda, envolvendo outra Ciência (Física) e construção de padrão algébrico 
por meio de uma sequência de valores. Esses exercícios, segundo o autor, ajudam os alunos a compreender o que são grandezas variáveis independentes e dependentes, a relação entre elas e como representá-las por uma fórmula matemática. Outros exercícios são relacionados ao comércio, eventos físicos e tabela de padrões. De acordo com o autor, o livro proporciona "grande variedade de exercícios e situações-problema para o aluno checar, consolidar a aplicar conhecimentos recentes" (DANTE, 2016, p. 304). Acreditamos que essas atividades aumentam a idoneidade epistêmica e cognitiva.

A escolha do problema 7 ocorreu por observarmos as dificuldades dos alunos em resolver esta situação-problema quando trabalhamos com este livro, em sala de aula. No exercício 7 , de acordo com a Figura 3, apresenta-se uma atividade em que 0 aluno deve aplicar conhecimentos prévios e conhecimentos emergentes de modelagem que é uma componente da idoneidade epistêmica. Dante (2016) propõe trabalhar a matemática por meio de situações-problema que façam o aluno pensar, analisar, julgar e decidir pela melhor solução.

Figura 3: Exercício 7

7. Um cabeleireiro cobra $R \$ 12,00$ pelo corte para clien-
tes com hora marcada e $R \$ 10,00$ sem hora marca-
da. Ele atende por dia um número fixo de 6 clientes
com hora marcada e um número variável $x$ de clien-
tes sem hora marcada.
a) Escreva no caderno a fórmula mate mática que
fornece a quantia $Q$ arrecadada por dia em fun-
ção do número $x$. $Q=72+10 x$
b) Qual foi a quantia arrecadada em um dia em que
foram atendidos 16 clientes? $R \$ 172,00$
c) Qual foi o número de clientes atendidos em um
dia em que foram arrecadados $R \$ 212,00$ ?
d) Qual é a expressão que indica o número $C$ de
clientes atendidos por dia em função de $x$ ?
$C=x+6$

Fonte: Dante (2016, p. 47).

A atividade é contextualizada do meio sociocultural dos alunos. Utiliza a linguagem verbal, adequada ao nível dos estudantes, conduzindo 0 aluno a adquirir a linguagem algébrica, modelar a situação-problema e construir conexões dentro e fora da própria matemática. Nessa atividade 0 aluno deverá aplicar conhecimentos prévios e construir novos conhecimentos por meio de argumentos e conjecturas. A atividade proposta no livro não apresenta erros, contradições e ambiguidades. Elas ajudarão os alunos a compreender o que são grandezas variáveis, o que são variáveis independentes e dependentes, a relação entre elas e como representá-las por uma fórmula matemática. Observamos que vários indicadores da idoneidade epistêmica, cognitiva e ecológica são mobilizados neste problema. A idoneidade interacional será mobilizada fazendo-se a atividade de forma dialogada e guiada pelo professor. O professor ao planejar suas aulas, não 
deve se ater somente ao livro didático. Ele precisa buscar por atividades complementares e enriquecedoras das aprendizagens. Dessa forma, ele cria condições para o aluno fazer conexões com os objetos matemáticos e seus significados correspondentes. Entendemos que algumas dessas conexões são realizadas durante a execução das atividades.

Observamos que os exemplos explorados pelo autor apresentaram função linear do tipo $y=k x$ e, essa nova situação-problema requer a descoberta de informações matemáticas desconhecidas para o estudante, em que ele deverá identificar que a função tem um valor constante e uma parcela variável e que é idêntica à função afim $y=a x+b$. Acreditamos que isso pode provocar conflito cognitivo, pois o aluno pode não perceber que existe uma parcela constante acrescida de outra que cresce linearmente. Neste momento o professor deverá interagir com os alunos e fazer propostas para que eles percebam que existe um valor constante, que não depende das variáveis. Ele deve sugerir a construção de uma tabela para facilitar a percepção do valor fixo, incentivando os alunos a fazerem transição entre as várias representações de funções, conduzindo os estudantes a chegarem na representação algébrica. Além disso, a resolução desse exercício deve ser dialogada entre alunos e professor, com o objetivo de provocar naqueles questionamentos e argumentações. A atividade requer que 0 aluno estabeleça conexão com aprendizados anteriores e formalize novos conhecimentos. $O$ professor deve mostrar-lhes a diferença entre a expressão analítica de uma função com a expressão analítica de uma equação e, ainda, mostrar o significado da variável em ambas as representações.

\section{Conclusões}

Neste texto foram trazidos alguns exemplos da noção intuitiva de função abordados pelo autor do livro didático. Em seguida, analisou-se uma atividade proposta aos alunos na sequência dos exercícios para aprendizagem e fixação do conteúdo, com o intuito de estabelecer o grau de adequação da atividade dentro da sequência de exercícios proposta pelo autor do livro. Para esta análise foram utilizadas as ferramentas de idoneidade (adequação) didática propostas pela teoria de EOS (GODINO, BATANERO, 1994; GODINO et al., 2006) e feita uma adaptação da guia de análise de livros didáticos proposta por Castillo, Burgos e Godino (2021). As facetas de idoneidade (adequação) epistemológica, cognitiva, instrucional e ecológica foram usadas como sugerido por esses pesquisadores espanhóis. Os potenciais conflitos são identificados quando se contrasta a trajetória epistêmica e cognitiva sobre o assunto. Essas informações são úteis aos docentes quando lançam mão do livro didático para planejar suas trajetórias didáticas para serem implementadas em suas aulas. 
A sequência dos exemplos introdutórios da noção intuitiva de funções pode levar 0 aluno a compreender a variação funcional entre as grandezas com identificação das variáveis independente e dependente, modelar a função linear e realizar cálculos simples de aplicação de valores na fórmula. Os exercícios propostos ao final da seção são contextualizados e diversificados, envolvendo conteúdo da própria matemática e de outras áreas, os quais atendem às orientações curriculares e, são manifestados vários indicadores das idoneidades epistêmica, cognitiva, interacional e ecológica. Essas atividades não apresentam grandes dificuldades e levam o aluno a recordar alguns conceitos da geometria plana, tais como: área, perímetro, diagonal, entre outros. A atividade analisada exige que 0 aluno mobilize conhecimentos prévios e, também, busque por alternativas diferentes, tais como: construir tabelas, transitar entre os tipos de representação de função, verificar a existência de padrão, investigar, conjecturar e buscar a solução. É interessante que a atividade seja realizada em duplas ou grupos para que os alunos dialoguem entre si na busca da solução ideal. Portanto, identificamos que existe integração entre essas idoneidades, o que pode favorecer a aprendizagem de estudantes. Segundo Godino et al. (2006, p. 226), "a aprendizagem tem um lugar mediante a participação do sujeito nas comunidades de prática, através da ligação progressiva dos significados pessoais aos institucionais e a apropriação dos significados institucionais pelos estudantes".

O professor utiliza o livro como recurso didático e ao planejar suas aulas pode modificar a trajetória epistêmica prevista na lição e articulá-la com as outras trajetórias cognitiva, instrucional e ecológica. O conceito de função é abordado adequadamente na obra, os indicadores das idoneidades epistêmica, cognitiva, instrucional e ecológica estão presentes nos exemplos e tarefas propostas pelo autor. A clareza de exposição e a diversidade de atividades propostas promovem aumento das idoneidades, e podem conduzir o estudante de ensino médio a compreender e aprender 0 conceito de função. 0 professor deve sugerir tarefas complementares abordando as outras representações para as funções e avaliar adequadamente a evolução progressiva da aprendizagem de seus alunos. Deve-se buscar por alternativas além do livro didático para proporcionar aos alunos aprendizagem do conceito de função. Em suma, o livro didático é um recurso pedagógico, mas não é o único.

\section{Referências}

ARMAS, Tulio Amaya de. Evaluación de la faceta epistémica del conocimiento didáctico matemático de futuros profesores de matemáticas en el desarrollo de uma classe utilizando funciones. Rio Claro - São Paulo, Bolema, v. 34, n. 66, p. 110-131, 2020. 
una función. 2106. Tese (Doctorado en Innovación e Invetigación em Didáctica) - Universidad Nacional de Educación a Distância. Colômbia, 2016.

ATAYDE, Alan Florêncio de. A abordagem de função nos livros didáticos: possibilidades de investigação, exploração, problema e exercícios. 2010. Dissertação (Mestrado Profissional em Ensino de Matemática) - Pontifícia Universidade Católica de São Paulo, São Paulo, 2010.

BARBOSA, Edelweis José Tavares. Praxeologia do professor: análise comparativa com os documentos oficiais e do livro didático no ensino de equações polinomiais do primeiro grau. 2017. Tese (Doutorado em Ensino de Ciências e Matemática) - Universidade Federal Rural de Pernambuco, Recife, 2017.

BARRETO, Antônio Luiz de Oliveira $A$ análise da compreensão do conceito de função mediado por ambientes computacionais. 2009. Tese (Doutorado em Educação Brasileira) Universidade Federal do Ceará, Fortaleza, 2009.

BLANCO, Glória Braga; DOMÍNGUEZ, José Luis Belver. El análisis de libros de texto: uma estratégia metodológica em la formación de los prefessionales de la educación. Oviedo, Revista Complutense de Educación, v. 27, n. 1, p. 199-218, 2014.

BRASIL, Ministério da Educação. Secretaria de Educação Básica. Orientações Curriculares Nacionais para Ensino Médio: Ciências da Natureza Matemática e suas Tecnologias. Brasília: MEC, v. 2, 2006.

BRASIL, Ministério da Educação. Secretaria de Educação Média e Tecnológica. Parâmetros Curriculares Nacionais: Ciências da Natureza Matemática e suas Tecnologias: PCN + Ensino Médio: Orientações Educacionais complementares aos Parâmetros Curriculares Nacionais. Brasília: MEC, 2002.

BRASIL, Ministério da Educação. Secretaria de Educação Média e Tecnológica. Parâmetros Curriculares Nacionais: Ensino Médio. Brasília: MEC, 2000.

BREDA, Adriana; FONT, Vicenç; PINO-FAN, Luiz Roberto. Critérios valorativos y normativos em la didáctica de las matemáticas: el caso del constructo idoneidade didáctica. Bolema, v.32, n. 60, p. 255-278, 2018.

BROETTO, Geraldo Cláudio. 0 ensino de números irracionais para alunos ingressantes na licenciatura em matemática. Tese (Doutorado em Educação) Universidade Federal do Espírito Santo, Espírito Santo, 2016.

BURGOS, Maria; CASTILLO, Maria José; PELLICER, Pablo Beltrán; GIACOMONE, Belén; GODINO, Juan Diáz. Análisis didáctico de una lección sobre proporcionalidade en un libro de texto de primária con herramientas del enfoque ontosemiótico. Bolema, Rio Claro, v. 34, n. 66, p. $40-68,2020$.

CASTILLO, Maria José; BURGOS, Maria; GODINO, Juan Diáz. Elaboración de uma guia de análisis de libros de exto de matemáticas basada em la teoria de la idoneidade didáctica.

Educação e Pesquisa, v. 47, p. 1 - 21, 2021.

DANTE, Luiz Roberto. Matemática, contexto \& aplicações. 3. ed., v. 1, São Paulo: Ática, 2016. 
FAN, Lianghuo; ZHU Yan; MIAO, Zhenzhen. Textbook research in mathematics education: development status and directions. ZDM Mathematics Education, USA, v. 45, p. 633-646, 2013.

FONSECA, Carla Isabel Teixeira Tavares Ribimbas. As funções exponencial e logarítmica nos manuais escolares do $12^{\circ}$ ano. 2013. Dissertação (Mestrado em Didática) - Universidade de Aveiro. Portugal, 2013.

FONT, Vicenc. Las funciones y la competência disciplinar em la formación docente matemática. UNO. Revista de Didáctica de las Matemáticas, v. 56, p. 86-94, 2011.

GODINO, Juan Diáz; BATANERO, Carmen Diáz. Significado institucional y personal de los objetos matemáticos. Recherches en Didactique des Mathèmatiques, v. 14, n. 3, p. 325-355, 1994.

GODINO, Juan Diáz. Um enfoque ontológico y semiótico de la cognición matemática. Paris, Recherches em Didactique des Mathématiques, v. 22, n. 2.3, p. 237-284, 2002.

GODINO, Juan Diáz; BENCOMO, Delisa; FONT, Vicenç; WILHELMI, Miguel R. Análisis y valoración de la idoneidade didactica de processos de estudo de las matemáticas. Espanha, Paradgma, v. 27, n. 2, p. 221-252, 2006.

GODINO, Juan Diáz; CONTRERAS, Ángel; FONT, Vicenç. Análisis de processos de instrucción basado en el enfoque ontológico - semiótico da la cognição matemática. Recherches em Didactique des Mathématiques. Paris, v.26. n. 1, p. 39 - 88, 2006.

GODINO, Juan Diáz; BATANERO, Carmen Diáz; FONT, Vicenç. The onto-semiotic approach research in mathematics education. ZDM Mathematics Education, n. 39, p. 127-135, 2007.

GODINO, Juan Diáz; BATANERO, Carmen Diáz; FONT, Vicenç. Um enfoque ontosemiótico del conocimiento y la instrución matemática. Acta Scientiae, Revista de Ensino de Ciências e Matemática, v. 10, n. 2, p. 7-37, 2008.

GODINO, Juan Diáz; BATANERO, Carmen; BURGOS, Maria; GEA, Maria M. Una perspectiva ontosemiótica de los problemas y métodos de investigación em educación matemática. Revemop, Ouro Preto, v. 3, p. 1 - 30, 2021. DOI: https://doi.org/10.33532/revemop.e202107

LOBO, Rogério dos Santos. A abordagem dada à taxa de variação no livro didático do ensino médio e a sua relação com o conceito da derivada no livro didático do ensino superior. 2017. Tese (Doutorado em Educação) - Pontifícia Universidade Católica de São Paulo, São Paulo, 2017.

MALET, Omar; GIACOMONE, Belén; REPETTO, Ana Maria. La idoneidade didáctica como herramienta metodológica: desarrollo y contextos de uso. Revemop, Ouro Preto, v. 3, p. 1 - 23, 2021. DOI: https://doi.org/10.33532/revemop.e202110

MASETTI, Cristina. Análise de livros didáticos de matemática: função exponencial. 2016. Dissertação (Mestrado em Educação Matemática) - Pontifícia Universidade Católica de São Paulo, São Paulo, 2016.

MELO, Marco André Pereira de. Ecologia do saber: o caso da análise combinatória em documentos oficiais e livros didáticos de educação básica. 2018. Tese (Doutorado em Educação Matemática e Tecnológica) - Universidade Federal de Pernambuco, Recife, 2018. 
NINOW, Valmir. 0 estudo de funções no ensino médio: uma investigação sob a perspectiva do enfoque ontossemiótico do conhecimento e da instrução matemática. Tese (Doutorado em Ensino de Ciências e Matemática) - Universidade Luterana do Brasil, Canoas, 2019.

ÖZER, Eren; SEZER, Renan. A comparative analysis of questions in American, Singaporean, and Turkish mathematics textbooks based on the topics covered in 8th grade in Turkey.

Educational Sciences:Theory \& Practice, Turquia, v. 14, n. 1, p. 411-421, 2014.

SANTOS, Leandra Gonçalves dos. Introdução do pensamento algébrico: um olhar sobre professores e livros didáticos de matemática. 2007. Dissertação (Mestrado em Educação) Universidade Federal do Espírito Santo, Vitória, 2007.

SIERPINSKA, Anna. On understanding the notion of function. In: Harel Guershon. The concept of function: Aspects of epistemology and pedagogy. USA: MAA, 1992. P. $25-58$.

SKEMP, Richard. R. Relational understanding and instrumental understanding. Mathematics Teaching, v. 77, p. 20-26, 1976.

SKEMP, Richard. R. The psychology of learning mathematics. England: Pinguin Books, 1993.

URREA, Yocelyn Elizabeth Parra. Significados pretendidos por el currículo de matemáticas chileno sobre la noción de funcion. 2015. Tese (Doutorado do Programa de Magíster en Educación Matemática) - Universidad de Los Lagos. Santiago, Chile, 2015.

VIEIRA, Vanice Silva Freitas. 0 ensino de Matemática proposto na coleção de livros didáticos usados nos cursos técnicos de nível médio do IFFluminense: contextos e aplicações. 2016. Tese (Doutorado em Ensino de Ciências e Matemática) - Universidade Cruzeiro do Sul, São Paulo, 2016.

YANG, Der-Ching; LIN, Yung-Chi. A comparison of functions in middle school textbooks among Finland, Singapore and Taiwan. In: INTERNATIONAL CONFERENCE ON MATHEMATICS TEXTBOOK RESEARCH AND DEVELOPMENT, Anais..., 2014, UK, University of Southampton, p. 505-510.

YILMAZ, Zuhal; GÜLBAGCI DEDE, H. Hand; AKKOÇ, Hatice. How to Introduce function concept in textbooks?: Evaluations of pre-service Mathematics Teachers. Necatibey. Faculty of Education. Electronic Journal of Science and Mathematics Education, v. 14, n. 1, p. 240-270, 2020.

ZUFFI, Edna Maura. 0 tema funções e a linguagem Matemática dos professores do ensino médio: por uma aprendizagem de significados.1999. Tese (Doutorado em Educação).

Universidade de São Paulo, São Paulo,1999. 